\title{
Identification of novel antiviral of fungus- derived brefeldin A against dengue viruses
}

\author{
Muhareva Raekiansyah', Mihoko Mori ${ }^{2,3}$, Kenichi Nonaka ${ }^{2,3}$, Masanobu Agoh', Kazuro Shiomi ${ }^{2,3}$, \\ Atsuko Matsumoto ${ }^{2,3}$ and Kouichi Morita ${ }^{1 *}$
}

\begin{abstract}
Microbial natural products possess a wide range of biological and biochemical potential. Among them, fungal secondary metabolites are one of the most important sources for discovering new drugs or lead compounds. In the present study, we explored substances produced by the strain Penicillium sp. FKI-7127 for its antiviral activity. We identified brefeldin A as a novel antiviral agent against dengue viruses. The inhibitory effect of brefeldin A was confirmed by virus titer and immunofluorescence assay. Brefeldin A inhibited dengue viruses regardless of serotypes and other related viruses including Zika virus and Japanese encephalitis virus. Time-of-addition study showed that brefeldin A exerts its antiviral effect at an early stage of the dengue virus (DENV) life cycle. These studies demonstrate that (i) brefeldin A could be used as a lead compound for drug development of anti-DENV and other related viruses and (ii) fungal metabolites are a potential and valuable source for dengue virus drug discovery.
\end{abstract}

Keywords: Dengue virus, Antiviral, Brefeldin A, Secondary metabolite, Fungus

\section{Introduction}

Dengue virus (DENV) is an important mosquito-borne pathogen for causing dengue fever (DF) and dengue hemorrhagic fever (DHF). DF is relatively mild, but DHF leads to the life-threatening dengue shock syndrome [1]. It is estimated that there are 390 million dengue infections per year, of which 96 million manifest apparently [2]. At present, no specific antiviral therapy for treatment of dengue disease is available. Thus, drug discovery research for dengue is of importance.

Natural products are valuable materials for the discovery and development of new drugs for treating many diseases since they possess a wide range of structural and functional diversity [3]. Among varied sources of natural products, secondary metabolites produced by fungi have been recognized as an important source of lead structures for new drugs [4].

Some bioactive compounds that are isolated and characterized from metabolites of soil-borne and endophytic fungi have led to the development of drugs such as anticancer drug Taxol which originated from endophytic-

\footnotetext{
*Correspondence: moritak@nagasaki-u.ac.jp

${ }^{1}$ Department of Virology, Institute of Tropical Medicine, Nagasaki University,

1-12-4 Sakamoto, Nagasaki 852-8523, Japan

Full list of author information is available at the end of the article
}

fungal metabolites [5]. Furthermore, a lot of antibacterial substances have been demonstrated from extracts and pure substances obtained from culture broth or fungal biomass [6]. Some studies have identified substances that inhibit viruses $[7,8]$. However, there are only few reports about DENV compounds found from fungal metabolites so far [9].

In this study, we examined anti-DENV activity of secondary metabolites produced by a fungal strain, Penicillium sp. FKI-7127. We isolated and identified brefeldin A (BFA) as a novel antiviral agent against DENVs. Inhibition of BFA on Japanese encephalitis virus (JEV) and Zika virus (ZIKV) was also demonstrated.

\section{Materials and methods}

\section{Cell lines and viruses}

Vero cells were maintained in a minimum essential medium supplemented with $10 \%$ fetal calf serum. The cells were grown at $37{ }^{\circ} \mathrm{C}$ with $5 \% \mathrm{CO}_{2}$. The strains used for this study were patient-derived DENV1-4 from the Philippines, strains 99st, 00st-22A, SLMC50, and SLMC318, respectively; Zika virus strain 976; and Japanese encephalitis virus (JEV) Beijing strain. 


\section{Microorganisms and culture of the fungal strain}

The fungal strain FKI-7127 was isolated from a soil around the root of Angelica keiskei collected in Kouzu Island, Tokyo, Japan. To observe the morphological characteristics, this strain was incubated on Miura's medium (LcA). From the results of morphological observation, the producing strain FKI-7127 was classified as genus Penicillium. The strain Penicillium sp. FKI-7127 was maintained on an LcA slant. A loopful of spores of this strain was inoculated into a test tube, containing $10 \mathrm{ml}$ of a seed medium consisting of $2 \%$ glucose, $0.5 \%$ Polypepton, $0.2 \%$ yeast extract, $0.2 \% \mathrm{KH}_{2} \mathrm{PO}_{4}, 0.05 \% \mathrm{MgSO}_{4} \cdot 7 \mathrm{H}_{2} \mathrm{O}$, and $0.1 \%$ agar, and incubated for 3 days. One milliliter of the seed culture was inoculated into each of two $500-\mathrm{ml}$ Erlenmeyer flasks containing $100 \mathrm{ml}$ of a production medium consisting of $3 \%$ soluble starch, $1.0 \%$ glycerol, $2 \%$ soybean meal, $0.3 \%$ dry yeast, $0.3 \% \mathrm{KCl}$, $0.2 \% \quad \mathrm{CaCO}_{3}, \quad 0.05 \% \quad \mathrm{KH}_{2} \mathrm{PO}_{4}, \quad 0.05 \% \quad \mathrm{MgSO}_{4} \cdot 7 \mathrm{H}_{2} \mathrm{O}$, and $0.03 \%$ quercetin dihydrate, and the production culture was incubated for 6 days. Fifty percent of ethanol extract of cultured broth were prepared for antiviral test.

\section{Antigen detection ELISA}

To evaluate the antiviral activity of a sample, Vero cells were seeded in 96-well plates $\left(1 \times 10^{4}\right.$ cells/well $)$ and infected with DENV at multiplicity of infection (MOI) of 0.5 in the presence of samples/compound or $0.1 \%$ dimethyl sulfoxide (DMSO). The cells were incubated for 3 days when infected culture fluid (ICF) was harvested and subjected for antigen detection enzyme-linked immunosorbent assay (ELISA) to determine dengue virus antigen level as described previously [10]. The result was expressed as a percent of inhibition which determined as (OD value of DMSO-treated cells) - (OD value of compound-treated cells $) \times 100 \%$ divided by $(\mathrm{OD}$ value of DMSO-treated cells).

\section{Cells viability assay}

Vero cells in 96-well plates were treated with samples for 5 days. Cell viability was evaluated by MTT [3-(4,5dimethylthiazol-2-yl)-2,5-diphenyl tetrazolium bromide] according to manufacturer's instruction (Promega).

\section{Isolation and identification of brefeldin A}

Cultured broth was extracted with $200 \mathrm{ml}$ of ethyl alcohol $(\mathrm{EtOH})$. After the mycelia were separated by centrifugation, the extract was evaporated to remove $\mathrm{EtOH}$. A part of the aqueous residue was applied to a Seppak plus ODS C18 cartridge and eluted with $\mathrm{H}_{2} \mathrm{O}-\mathrm{CH}_{3} \mathrm{CN}$ system to give five fractions (pass through 100:0, 70:30, 40:60, and 0:100 each $3 \mathrm{ml}$ ). Brefeldin A was detected in both 40:60 fraction and 0:100 fraction by high-performance liquid chromatography (HPLC) analysis, and identification of brefeldin A was achieved by high-resolution electrospray ionization mass spectrometry (HR-ESI-MS) and nuclear magnetic resonance (NMR) measurement.

\section{Immunofluorescence assay}

Vero cells in a 24-well plate were infected with DENV-2 and added with BFA. After $48 \mathrm{~h}$, infected cells were recovered, washed with PBS, and spotted onto a glass slide. Immunostaining was done as described previously [11].

\section{Time-of-addition studies}

Time-of-addition studies were performed in 96-well plate cells as follows. (i) Pre-infection assay: Vero cells were treated with $125 \mathrm{nM}$ BFA or $0.1 \%$ DMSO as control for $2 \mathrm{~h}$ at $37^{\circ} \mathrm{C}$ prior to being washed twice with PBS and infected with DENV-2 at an MOI of 10. After $1.5 \mathrm{~h}$ virus adsorption, the cells were washed twice with PBS and incubated in fresh media for $24 \mathrm{~h}$ before ICFs were harvested for virus quantification. (ii) During-infection assay: Vero cells were infected with DENV-2 in the presence of BFA. After $1.5 \mathrm{~h}$ virus adsorption, inoculum was removed and the cells were washed twice. The cells were then incubated with fresh media for $24 \mathrm{~h}$ before ICFs were harvested for virus quantification. (iii) After-infection assay: Vero cells were infected with DENV-2. After virus adsorption and washing, BFA or $0.1 \%$ DMSO as control was added at seven different time points postinfection $(0,2,4$, $6,8,12$, and $18 \mathrm{~h}$ ). The ICFs were harvested at $24 \mathrm{hpi}$ for virus quantification.

\section{Virus titration and focus reduction assay}

Virus titers were determined using Vero cells in 96-well plates as described previously [11]. In brief, virus stock or ICFs were diluted tenfold in the MEM and inoculated to the cells. After 60 min of virus adsorption, the MEM containing $2 \%$ FCS and $1.25 \%$ methylcellulose was overlaid on the cells. The cells were then incubated for 2 to 4 days before subjected to focus staining. For focus staining, 12D11/7E8 monoclonal antibody and HRP-conjugated goat anti-mouse $\operatorname{IgG}+\mathrm{M}$ were used as a primary and secondary antibody, respectively. The infected cells were visualized with 3,3'-diaminobenzidine, tetrahydrochloride (DAB). For focus reduction assay, Vero cells in 96-well plates were infected with DENV-1, 2, 3, 4, ZIKV, or JEV at an MOI of 0.5 in the presence of BFA at different concentrations. After $48 \mathrm{~h}$ incubation, ICFs were harvested. A 
hundred microliters of diluted ICFs (100x or $1000 \times$ dilution) was infected into fresh Vero cells in 96-well plates and incubate for another 2 to 4 days. The cells were then subjected for focus staining as described above. Experiments were performed twice, duplicating each.

\section{Results and discussion}

Identification of antiviral substance in the present study was part of our drug screening study for new dengue drug discovery. We employed cell-based assay in combination with in-house antigen detection ELISA to evaluate antiDENV activity. This technique was relatively quick and can be applied for high-throughput screening.

In initial testing, the crude extract from cultured broth of fungal strain Penicillium sp. FKI-7127 showed pronounced inhibition on DENV growth as determined from the reduction of antigen level in infectious culture fluid (data not shown). After optimization of culture condition which gave the highest inhibition or highest yield, two rounds of fractionation from large-scale culture broth were performed. Thirty-six final fractions were collected from HPLC fractionation, and each fraction was tested for its antiviral activity. We found that fraction \#17 that showed the highest peak in chromatogram (Fig. 1a) is the active fraction.

Inhibitory effect and cytotoxicity of fraction \#17 were further evaluated in increasing dilution (Fig. 1b). Fraction \#17 inhibited DENV-2 in a dose-dependent manner. The $50 \%$ cytotoxic concentration $\left(\mathrm{CC}_{50}\right)$ of the fraction after 5 days of simultaneous incubation was $>16 \times$, the lowest dilution tested.

We next performed the identification of active components in fraction \#17. Using HR-ESI-MS and NMR methods, brefeldin A was revealed as an active compound (Fig. 1c).

To confirm antiviral activity of BFA, we purchased BFA (Wako, Japan) and performed virus titration and immunofluorescence assay (IFA). BFA effectively inhibited DENV-2 growth as determined by virus titer. At a concentration of $250 \mathrm{nM}$, no virus was detected both at 24 and $48 \mathrm{~h}$ postinfection (Fig. 2a). Half maximal inhibitory
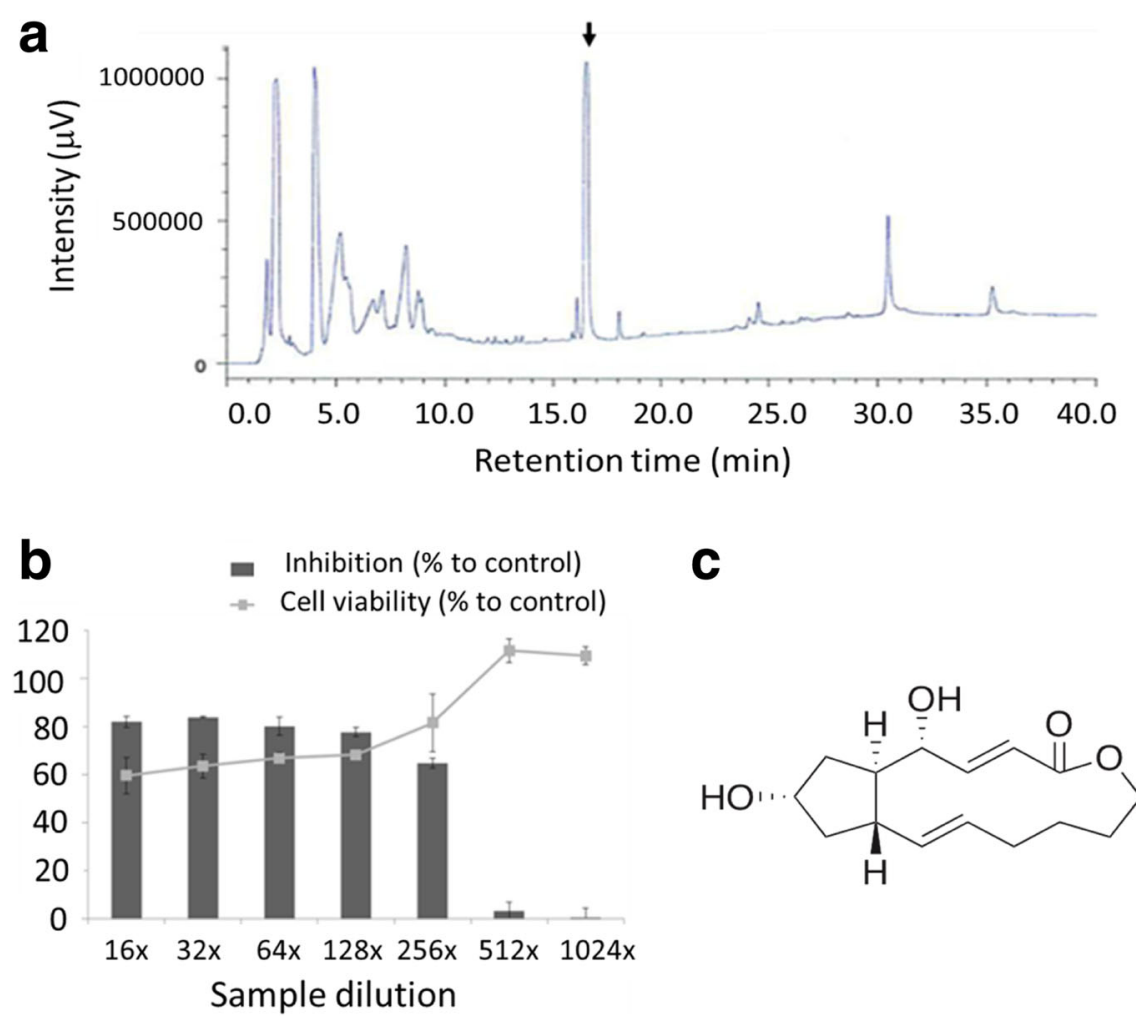

C<smiles>C[C@H]1CCC/C=C/[C@H]2C[C@H](O)C[C@H]2[C@H]1O</smiles>

Fig. 1 Identification of brefeldin A as DENV inhibitor. a Fractions of aqueous residue of cultured broth were applied to HPLC. HPLC chromatogram is shown, whereas peak of active molecule (fraction \#17) was indicated with an arrow. b Vero cells in 96-well plates were infected with DENV at an MOI of 0.03 in the presence of fraction \#17 with increasing dilutions. The cells were incubated for 5 days at $37^{\circ} \mathrm{C}$ in $5 \% \mathrm{CO}_{2}$ after which ICFs were harvested and subjected for antigen detection ELISA. In separated experiments, Vero cells in 96-well plates were treated with the fractions with increasing dilutions without virus infection. After 5 days incubation, cell viability was determined by MTT assay as described in the "Materials and methods" section. The error bars represent standard deviation from the means of the results from triplicate determination. c By HR-ESI-MS and NMR methods, the fraction \#17 was identified as brefeldin A. Structural formula of BFA is depicted 


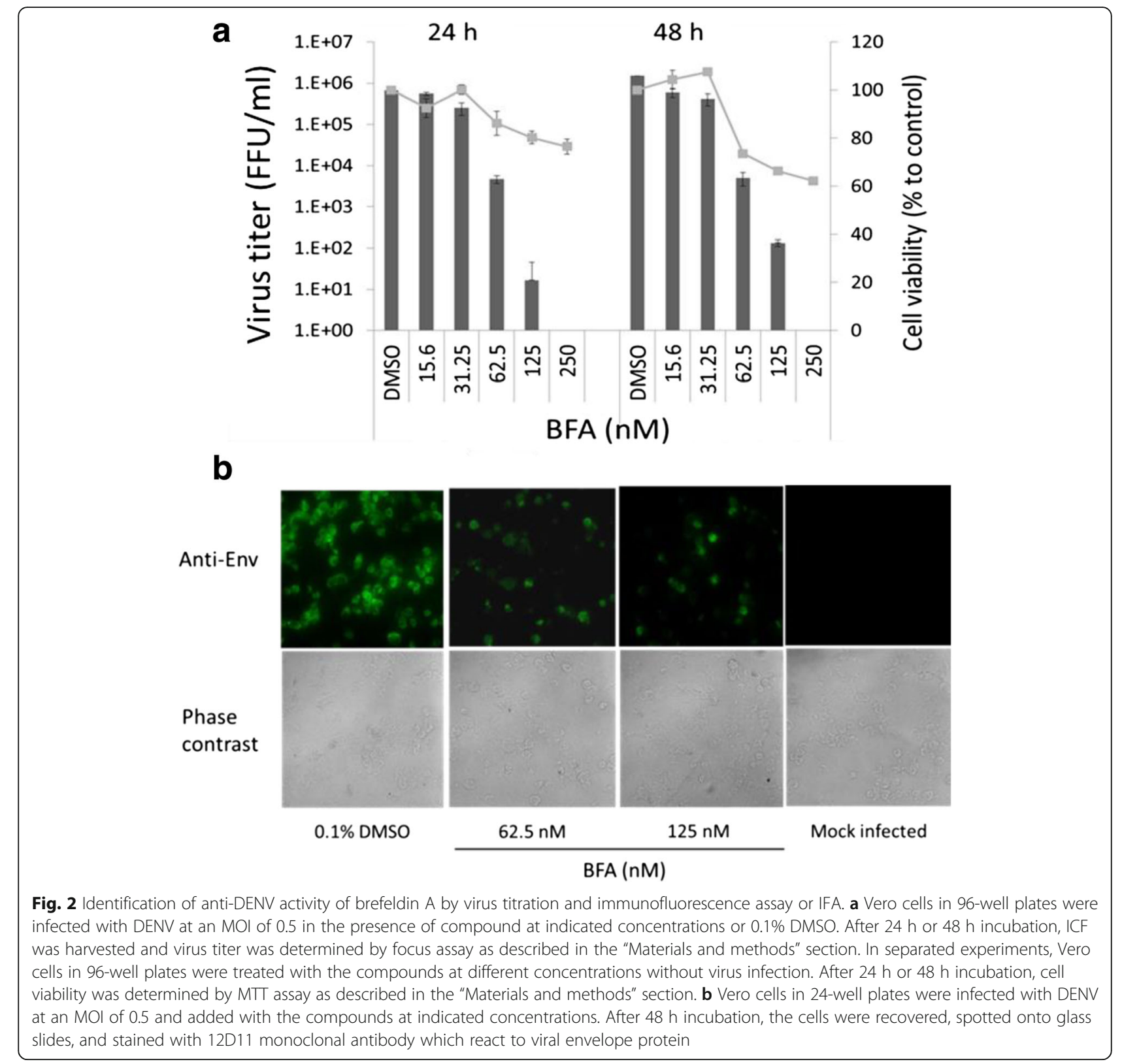

concentration $\left(\mathrm{IC}_{50}\right)$ value and $\mathrm{CC}_{50}$ of $\mathrm{BFA}$ at $48 \mathrm{~h}$ postinfection were $54.6 \pm 0.9$ and $2000 \mathrm{nM}$, respectively (Table 1). In line with virus titration results, IFA staining showed significantly decreased viral protein level by addition of BFA at concentrations of 62.5 and $125 \mathrm{nM}$ (as indicated by green fluorescence) suggesting that DENV-2 replication was strongly inhibited (Fig. 2b). Taken together, these results demonstrated BFA isolated from fungal strain Penicillium sp. FKI-7127 as an inhibitory agent against DENV.

BFA is a fungal secondary metabolite which was first isolated from Penicillium decumbens [12]. BFA has

Table 1 Antiviral activity of BFA against DENV-1 to 4, ZIKV, and JEV in Vero cell

\begin{tabular}{|c|c|c|c|c|c|c|}
\hline \multicolumn{6}{|l|}{$\mathrm{IC}_{50}(\mathrm{nM})^{\mathrm{a}}$} & \multirow[t]{2}{*}{$C C_{50}(n M)^{b}$} \\
\hline DENV-1 & DENV-2 & DENV-3 & DENV-4 & ZIKV & JEV & \\
\hline $61.3 \pm 13.5$ & $54.6 \pm 0.9$ & $57.9 \pm 0.1$ & $65.7 \pm 6.3$ & $54.8 \pm 0.4$ & $58.4 \pm 0.3$ & 2000 \\
\hline
\end{tabular}

All calculation was performed by using GraphPad Prism software. All values are the results from two independent experiments

${ }^{\mathrm{a}} \mathrm{I}_{50}-50 \%$ inhibitory concentration of BFA were calculated from the results of the virus titer determined by focus-forming assay

${ }^{\mathrm{b}} \mathrm{CC}_{50}-50 \%$ cytotoxic concentration of BFA were calculated from the dose-response curve 
various biological actions including antitumor and antibacterial activities [13]. BFA has also been reported to have antiviral activities against some viruses including poliovirus [14] and Rotavirus [15]. Recently, Zhou et al. demonstrated the inhibitory effect of BFA on Japanese encephalitis virus (JEV) in BHK-21 cells [16]. To our knowledge, this is the first report to demonstrate antiviral activity of BFA on DENV.

Antiviral activity of BFA against all DENV serotypes as well as two related viruses including ZIKV and JEV was also analyzed by focus reduction assay. Addition of BFA reduced focus number in a dose-dependent manner which indicates virus inhibition. BFA inhibited not only DENV-2 but also all other serotypes. Furthermore, strong inhibition of ZIKV and JEV by BFA was also demonstrated (Fig. 3). Determined by virus titer, the $\mathrm{EC}_{50}$ of BFA against DENV-1, 3, and 4, ZIKV, and JEV at $48 \mathrm{~h}$ postinfection/treatment were $61.32 \pm 13.5,57.9 \pm 0.1,65.7 \pm 6.3,54.8 \pm 0.4$, and $58.4 \pm 0.3 \mathrm{nM}$, respectively (Table 1 ).

In order to identify the window in the DENV replication cycle when BFA exerts its antiviral effect, time-

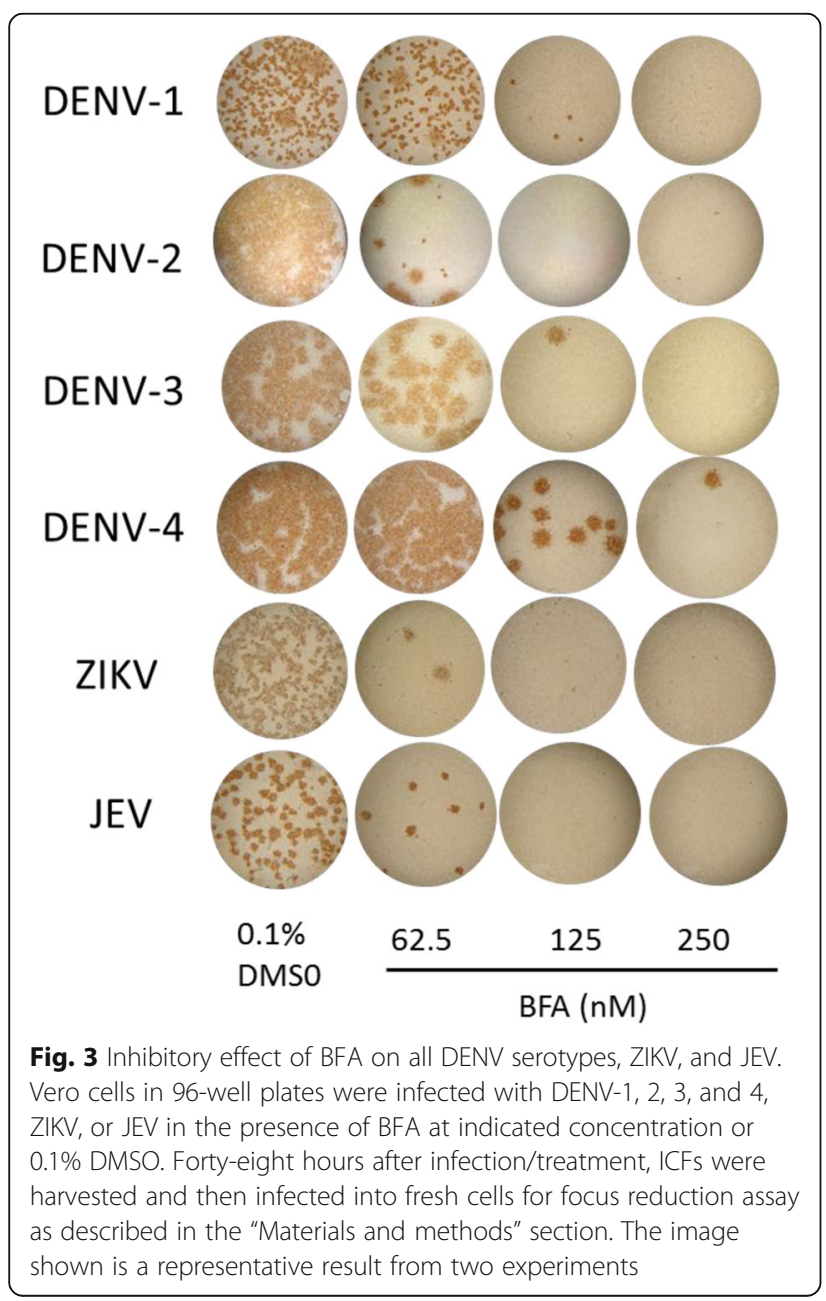

of-addition studies were performed in different treatments (Fig. 4a). During a single flavivirus life cycle, viral proteins are translated from genomic RNA in the first $1-5 \mathrm{~h}$ postinfection (hpi) followed by viral RNA synthesis which occurs after 5 hpi and progeny virus assembly and release after 12 hpi [17]. As shown in Fig. 4b, BFA does not interfere in the DENV entry process in the host cells. A significant reduction of the DENV titer was observed when BFA was added at the 0-hpi up to 4-hpi time points. After $4 \mathrm{hpi}$, inhibitory effect of BFA was gradually reduced. Addition of BFA at $18 \mathrm{hpi}$ resulted in complete loss of inhibition of DENV replication. These results suggested that BFA inhibits DENV at an early phase in the viral replication cycle that occurs after viral entry.

The time-of-addition study results are in line with an already known mode of action of BFA. BFA has been known to inhibit protein transport from the endoplasmic reticulum (ER) to the Golgi apparatus indirectly by interfering with the function of the Golgi apparatus [18]. BFA disturbs maturation and egress of herpes simplex virus particles during infection [19]. BFA has also been reported to interfere processing and secretion of the envelope of glycoproteins of HIV-1 in T-lymphoblast cells leading to inhibition of viral particle formation [20]. In case of poliovirus, BFA inhibits viral RNA synthesis by preventing the formation of secretory vesicles [21]. We speculate that, like other enveloped viruses, BFA inhibits the maturation of the DENV, ZIKV, and JEV by directly blocking the trafficking of glycoprotein from the ER to Golgi apparatus leading to the prevention of formation and release of the viruses from infected cells. In addition in our study, no inhibitory effect of BFA on DENV was shown in C6/36 cells (data not shown) indicating that BFA could not block intracellular protein transport in mosquito cell line.

Despite the fact that BFA possesses antiviral activity as demonstrated in this study and other previous studies, its toxicity would become a crucial issue in order to develop it as antiviral agents. Toxicity of BFA indeed is not unexpected because it targets Golgi apparatus which eventually causes cell death. However, BFA could be served as a lead compound. In the future, it can be structurally and phenotypically optimized by reducing its toxicity. Furthermore, its antiviral activity can also be improved through derivative analyses or another approaches.

Aside from its antiviral property, mechanism of disruption of the proper vesicular transport between ER and Golgi by BFA which is a critical step for the viral replication and release could provide a new tool to characterize the lifecycle of the virus. It is also possible to help researchers develop novel inhibitors of DENV and other viruses. 


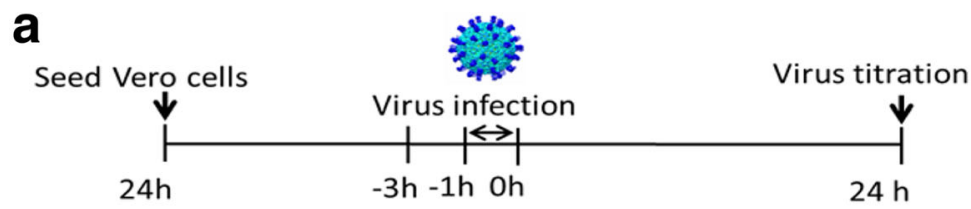

Pre-infection

During infection

After infection (0 -24 h)

$(2-24 h)$

$(4-24 h)$

$(6-24 h)$

$(8-24 h)$

(12 -24 h)

$(18-24 h)$

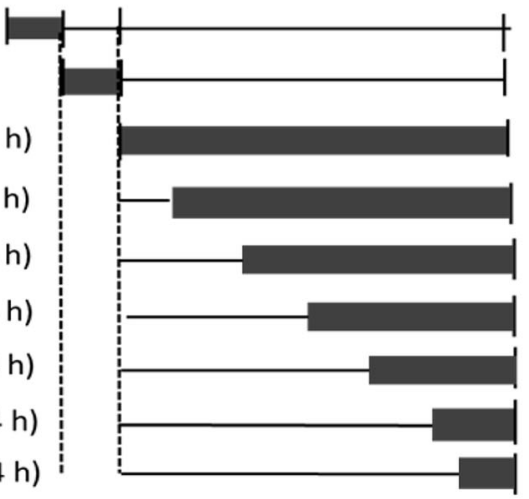

$125 \mathrm{nM} \mu \mathrm{M}$ BFA or DMSO $\longmapsto$ Without compound

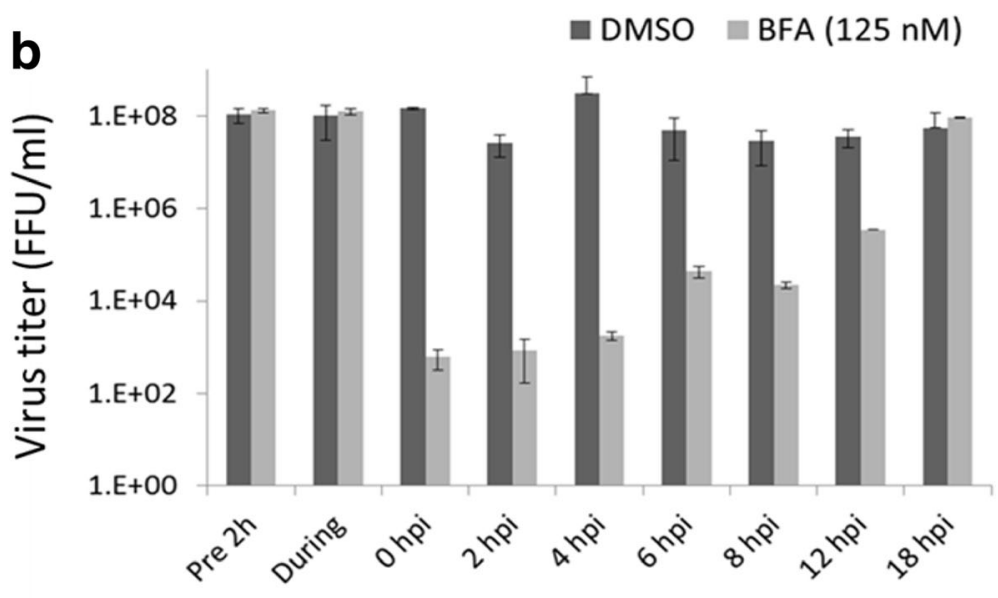

Time course of BFA treatment on infected cells

Fig. 4 Time-of-addition studies. a Schematic illustration of time-of-addition studies for treatment with BFA. Vero cells in 96-well plates were treated with $125 \mathrm{nM} \mathrm{BFA}$ at different time points before, during, and after DENV infection (MOI of 5). For after-infection assay, BFA was added at seven different time points after virus exposure. b After $24 \mathrm{~h}$ postinfection, released virus titer was determined by focus assay as described in the "Materials and methods" section. Error bars represent standard errors of two independent experiments

\section{Conclusion}

In conclusion, here we isolated, identified, and characterized an anti-DENV agent of fungus-derived BFA which is potentially used as a lead compound for drug development of anti-DENV and other related viruses. Fungal secondary metabolites are a potential and valuable source in drug screening for the development of antiviral agents.

\section{Abbreviations}

BFA: Brefeldin A; CC 50 : The $50 \%$ cytotoxic concentration; DENV: Dengue virus; DF: Dengue fever; DHF: Dengue hemorrhagic fever; DMSO: Dimethyl sulfoxide; ELISA: Enzyme-linked immunosorbent assay; HPLC:

High-performance liquid chromatography; $\mathrm{IC}_{50}$ : Half maximal inhibitory concentration; IFA: Immunofluorescence assay; JEV: Japanese encephalitis virus; ZIKV: Zika virus

Acknowledgements

Not applicable.

Funding

This research was supported by the Japan Initiative for Global Research Network on Infectious Diseases (J-GRID) of Japan Agency for Medical Research and Development (AMED).

Availability of data and materials Not applicable. 


\section{Authors' contributions}

$\mathrm{KM}$ and $\mathrm{MR}$ conceived and designed the study. MR, MM, KN, MA, and AM performed the experiments. MR, MM, KS, AM, and KM analyzed the data. MR, $\mathrm{MM}, \mathrm{KN}, \mathrm{KS}$, and $\mathrm{KM}$ wrote the paper. All authors read and approved the final manuscript.

\section{Ethics approval and consent to participate}

Not applicable.

\section{Consent for publication}

Not applicable.

\section{Competing interests}

The authors declare that they have no competing interests.

\section{Publisher's Note}

Springer Nature remains neutral with regard to jurisdictional claims in published maps and institutional affiliations.

\section{Author details}

${ }^{1}$ Department of Virology, Institute of Tropical Medicine, Nagasaki University, 1-12-4 Sakamoto, Nagasaki 852-8523, Japan. ${ }^{2}$ Kitasato Institute for Life Sciences, Kitasato University, 5-9-1 Shirokane, Minato-ku, Tokyo 108-8641, Japan. ${ }^{3}$ Graduate School of Infection Control Sciences, Kitasato University, 5-9-1 Shirokane, Minato-ku, Tokyo 108-8641, Japan.

Received: 18 August 2017 Accepted: 9 October 2017

Published online: 26 October 2017

\section{References}

1. Simmons CP, Farrar JJ, Nguyen W, Wills B. Dengue. N Engl J Med. 2012;366:1423-32

2. Bhatt $\mathrm{S}$, Gething PW, Brady OJ, Messina JP, Farlow AW, Moyes $\mathrm{CL}$, et al. The global distribution and burden of dengue. Nature. 2013;496:504-7.

3. Cragg GM, Newman DJ. Natural products: a continuing source of novel drug leads. Biochim Biophys Acta. 2013;1830:3670-95.

4. Demain AL, Martens E. Production of valuable compounds by molds and yeasts. J Antibiot. 2017;70:347-60.

5. Strobel G, Yang X, Sears J, Kramer R, Sidhu RS, Hess WM. Taxol from Pestalotiopsis microspora, an endophytic fungus of Taxus wallachiana. Microbiology. 1996;142:435-40.

6. Radić N, Strukelj B. Endophytic fungi: the treasure chest of antibacterial substances. Phytomedicine. 2012;19:1270-84.

7. Bunyapaiboonsri T, Yoiprommarat S, Srikitikulchai $P$, Srichomthong K, Lumyong S. Oblongolides from the endophytic fungus Phomopsis sp. BCC 9789. J Nat Prod. 2010;73:55-9.

8. Roy BG. Potential of small-molecule fungal metabolites in antiviral chemotherapy. Antiviral Chem Chemother. 2017:25:20-52.

9. Estoppey D, Lee CM, Janoschke M, Lee BH, Wan KF, Dong H, et al. The natural product cavinafungin selectively interferes with Zika and dengue virus replication by inhibition of the host signal peptidase. Cell Rep. 2017;19:451-60.

10. Ngwe Tun MM, Kyaw AK, Makki N, Muthugala R, Nabeshima T, Inoue S, et al. Characterization of the 2013 dengue epidemic in Myanmar with dengue virus 1 as the dominant serotype. Infect Genet Evol. 2016;43:31-7.

11. Raekiansyah M, Espada-Murao LA, Okamoto K, Kubo T, Morita K. Dengue virus neither directly mediates hyperpermeability nor enhances tumor necrosis factor-a-induced permeability in vitro. Jpn J Infect Dis. 2014;67:86-94.

12. Singleton $\mathrm{VL}$, Bohonos N, Ullstrup AJ. Decumbin, a new compound from a species of Penicillium. Nature. 1958;181:1072-3.

13. Betina V. Biological effects of the antibiotic brefeldin A (decumbin, cyanein, ascotoxin, synergisidin): a retrospective. Folia Microbiol (Praha). 1992;37:3-11.

14. Cuconati A, Molla A, Wimmer E, Brefeldin A. Inhibits cell-free, de novo synthesis of poliovirus. J Virol. 1998;72:6456-64.

15. Mirazimi A, von Bonsdorff $\mathrm{CH}$, Svensson L. Effect of brefeldin A on rotavirus assembly and oligosaccharide processing. Virology. 1996;217:554-63.

16. Zhou J, Wang SQ, Wei JC, Zhang XM, Gao ZC, Liu K, et al. Mx is not responsible for the antiviral activity of interferon-a against Japanese encephalitis virus. Viruses. 2017;9:5.
17. Chambers TJ, Hahn CS, Galler R, Rice CM. Flavivirus genome organization, expression, and replication. Annu Rev Microbiol. 1990;44:649-88.

18. Lippincott-Schwartz J, Yuan LC, Bonifacino JS, Klausner RD. Rapid redistribution of Golgi proteins into the ER in cells treated with brefeldin A: evidence for membrane cycling from Golgi to ER. Cell. 1989;56:801-13.

19. Cheung P, Banfield BW, Tufaro F, Brefeldin A. Arrests the maturation and egress of herpes simplex virus particles during infection. J Virol. 1991;65:1893-904.

20. Pal R, Mumbauer S, Hoke GM, Takahashi A, Sarngadharan MG, Brefeldin A. Inhibits the processing and secretion of envelope glycoproteins of human immunodeficiency virus type 1. AIDS Res Hum Retrovir. 1991;7:707-12.

21. Maynell LA, Kirkegaard K, Klymkowsky MW. Inhibition of poliovirus RNA synthesis by brefeldin A. J Virol. 1992;66:1985-94.

\section{Submit your next manuscript to BioMed Central and we will help you at every step:}

- We accept pre-submission inquiries

- Our selector tool helps you to find the most relevant journal

- We provide round the clock customer support

- Convenient online submission

- Thorough peer review

- Inclusion in PubMed and all major indexing services

- Maximum visibility for your research

Submit your manuscript at www.biomedcentral.com/submit
Biomed Central 